\title{
Exploring the Relationship between Design Science Research and Innovation: A Case Study of Innovation at Chevron
}

\author{
Jack Anderson, Chevron Corporation, \\ Brian Donnellan, National University of Ireland Maynooth \\ Alan Hevner, University of South Florida
}

\begin{abstract}
What is the relationship between design science research and innovation? Our industry-academic collaboration poses this intriguing question and suggests a context and an experimental design for its study. We wish to understand the synergies between the active research areas of DSR and innovation by exploring their overlapping concepts and identifying unique ideas in each that have the potential to inform the other. We present a case study of an actual innovation process in Chevron as a source of empirical data for the exploration and subsequent analysis of how the application of DSR guidelines might inform the practical implementation of innovation processes.
\end{abstract}

Keywords: Design Science Research, Innovation, Case Study Research, Artefact, Evaluation 


\section{Exploring the Relationship between Design Science Research and Innovation: A Case Study of Innovation at Chevron}

\section{Introduction}

In business and industry, innovation is the catalyst to growth. Continual innovation is essential for companies to maintain a competitive advantage in their field of production or service (Porter 1998). Schumpeter (1943) famously argued that industries must incessantly revolutionize their economic structure from within, that is, they must innovate with new processes and products. Innovation is closely aligned with the emergence of entrepreneurs who form new companies based upon new products and services with some combination of improved quality, durability, service, and price. Academia has recognized the growing important and interest in innovation studies with new educational programs and research journals.

In this study, we propose to explore the relationship between Design Science Research (DSR) and Innovation, particularly in the areas of information and communications technologies and systems (ICTS). What are the synergies between the research streams on these two topics and how can we identify and exploit the commonalities and differences? In particular we examine the implementation of an actual innovation process in Chevron as a case study and explore how the application of DSR guidelines might enhance innovation practices in that organization. This work is particularly appropriate now because of the current focus on innovation as a source of competitive advantage and the growing momentum in IS research relating to IS-enabled business transformation.

We begin by discussing the Hevner et al. (2004) guidelines for DSR in Section 2. Section 3 then surveys the innovation literature for matching guidance. The Chevron innovation case study is presented in Section 4. Via the case study, examples of alignment and gaps between the two fields are investigated. Section 5 briefly highlights the findings of the case study. Section 6 concludes the paper with the discussion of our research approach to study the issues raised in our comparisons of the two research streams.

\section{Design Science Research Guidelines}

Design activities are central to most applied disciplines. Research in design has a long history in many fields including architecture, engineering, education, psychology and the fine arts (Cross 2001). The ICTS field since its advent in the late 1940's has appropriated many of the ideas, concepts, and methods of design science that have originated in these other disciplines. However, information systems (IS) as composed of inherently mutable and adaptable hardware, software, and human interfaces provide many unique and challenging design problems that call for new and creative ideas, e.g. innovations.

The DSR paradigm is highly relevant to information systems research because it directly addresses two of the key issues of the discipline: the central role of the IT artefact in IS research (Weber 1987; Orlikowski and Iacono 2001; Benbasat and Zmud 2003) and the perceived lack of relevance of IS research to the business community (Benbasat and Zmud 1999). The design science paradigm has its roots in engineering and the sciences of the artificial (Simon 1996). It is fundamentally a problem-solving paradigm. It seeks to create innovations that define the ideas, practices, technical capabilities, and products through which the analysis, design, implementation, and use of information systems can be effectively and efficiently accomplished.

The primary goal of the Hevner et al. (2004) MISQ paper is to provide an understanding of how to conduct, evaluate, and present DSR to IS researchers and practicing business managers. The research activities of design science within the IS discipline are described via a conceptual framework for understanding information systems research and a clear set of seven guidelines are proscribed for 
conducting and evaluating good design science research. A detailed discussion of each of the seven guidelines is presented in the $M I S Q$ paper. The proposed guidelines as summarized below provide a basis for understanding and evaluating the processes and products of DSR.

\subsection{Design as an Artefact}

The result of design science research in ICTS is, by definition, a purposeful artefact created to address an important organizational problem. Hevner et al. (2004) define the artefact as the constructs, models, methods, and instantiations applied in the development and use of information systems. Artefacts are innovations that provide a degree of novelty into an application context. Some aspect of the artefact must be an original contribution to the existing knowledge base of the application domain. Thus, we posit that artefact originality is a defining characteristic of DSR which makes the new artefact an innovation to the field of application.

\subsection{Problem Relevance}

Pragmatic design science research begins by identifying and representing opportunities and problems in an actual application environment. The goal of relevance initiates DSR with an application context that not only provides the requirements for the research (e.g. the opportunity/problem to be addressed) as inputs but also defines acceptance criteria for the ultimate evaluation of the research results in real-world contexts (Hevner 2007).

\subsection{Design Evaluation}

The utility, quality, and efficacy of a design artefact must be rigorously demonstrated via well-executed evaluation methods. Evaluation is a crucial component of the DSR process. Because design is inherently an iterative and incremental activity, the evaluation phase provides essential feedback to the construction phase as to the quality of the design process and the design product under development. A design artefact is complete and effective when it satisfies the requirements and constraints of the problem it was meant to solve (Simon 1996). Evaluation approaches and techniques must be rigorously appropriated from the research knowledge base.

\subsection{Research Contributions}

Design science research must provide contributions to both the application environment in the form of a problem-solving artefact and an addition to the field's knowledge base. Additions to the knowledge base will include any extensions to the original theories and methods made during the research, the new artefacts (design products and processes), and all experiences gained from performing the iterative design cycles and field testing of the artefact in the application environment. It is imperative that a design research project makes a compelling case for its rigorous bases and contributions lest the research be dismissed as a case of routine design.

\subsection{Research Rigor}

Rigor addresses the way in which research is conducted. DSR requires the application of rigorous methods in both the construction and evaluation of the designed artefact. Rigor is derived from the effective use of the knowledge base - theoretical foundations and research methodologies. Success is predicated on the researcher's skilled selection of appropriate techniques to develop or construct an artefact and the selection of appropriate means to evaluate the artefact.

\subsection{Design as a Search Process}

Design, as a verb, is essentially a search process to discover an effective solution to a problem. Problem solving can be viewed as utilizing available means to reach desired ends while satisfying laws existing in 
the environment (Simon 1996). Abstraction and representation of appropriate means, ends, and laws are crucial components of DSR. These factors are problem and environment dependent and invariably involve creativity and innovation. Means are the set of actions and resources available to construct a solution. Ends represent goals and constraints on the solution. Laws are uncontrollable forces in the environment. Effective design requires knowledge of both the application domain (e.g. requirements and constraints) and the solution domain (e.g. technical and organizational).

\subsection{Communication of Research}

The goal of a design researcher is to publish in top journals in the application field. Any discussion of top-quality publication outlets must draw a distinction between journals with technology-focused audiences and management-focused audiences. Good DSR produces results of interest for both audiences. Technology audiences need sufficient detail to enable the described artefact to be constructed (implemented) and used within an appropriate context. It is important for such audiences to understand the processes by which the artefact was constructed and evaluated. This establishes repeatability of the research project and builds the knowledge base for further research extensions by future researchers.

On the other hand, management audiences need sufficient detail to determine if organizational resources should be committed to constructing (or purchasing) and using the artefact within their specific organizational context. The rigor of the artefact design process must be complemented by a thorough presentation of the experimental design of the artefact's field test in a realistic organizational environment. The emphasis must be on the importance of the problem and the novelty and utility of the solution approach realized in the artefact.

\section{Innovation Research}

\subsection{Innovation Definitions}

The voluminous and eclectic innovation literature has been described by Adams et al. (2006) as a "fragmented corpus." In an antecedent paper, Wolfe (1994 p. 405) concluded that it had made little contribution to the understanding of innovative behavior in organizations and his evaluation of the results as being "inconclusive, inconsistent and characterized by low levels of explanation" was surely a pointed criticism of the field. Slappendel's subsequent (1996) mapping of the literature on innovation in organizations in terms of three theoretical regions; the individualist perspective, the structuralist perspective, and the interactive process perspective; has been applied by the IS community to the analysis of software process improvement (SPI) innovations (Kautz \& Nielsen 2004).

More recently, there have been some noteworthy attempts to provide a more holistic appreciation of the innovation landscape such as the compilations by Fagerberg et al. (2005) and by Shavinina (2003). However, Fagerberg's (2005 p. 20) conclusion that "our understanding of how knowledge-andinnovation operates at the organizational level remains fragmentary" and "that further conceptual and applied research is needed" indicates a scarcity of progress in the intervening period. Avgerou (2002 p 141) comes to the striking conclusion that "the term innovation is not actually widely used" in the information systems literature. Swanson (1994 p 1069), who has been notable among the IS research community in addressing the subject, argues that the innovative deployment of information technology is "increasingly crucial to competitive survival and success."

\subsection{IS Innovation Process Management Frameworks}

Information System (IS) innovation has been described as any new way of developing, implementing, and maintaining information systems in an organizational context (Swanson 1994). A so-called "resource-based" view of IS innovation has been popular in the literature (Feeny and Willcocks 1998). This view sees the ability to leverage IS in new ways as being a core competence of an organization and a source of sustainable competitive advantage. Resources that might lead to competitive advantage may 
include proprietary IS technology and unique IS technical and/or management skills. Peppard et al. (2000) examined the problem of value creation from IS investments from an organizational as opposed to an IS functional perspective. Drawing on resource-based theory, the authors argued that the effective deployment and exploitation of information should be viewed as a 'strategic asset.' To leverage value from IS, the authors proposed that organizations must recognize and develop information management competencies and that the elements of these competencies should be distributed throughout the organization and not be solely resident in the IS function. They characterized these competencies as being of three types: information strategy, information exploitation, and IT/IS supply. Furthermore, in Peppard and Ward (2004) the authors developed a model linking the IS capability with IS competencies and resources.

Friedman and Cornford (1989) classify IS process innovations into three evolutionary generations; based on an extensive empirical analysis of the historical evolution of IS development:

- $\quad$ technological changes in hardware and software

- $\quad$ changes in types of systems being developed; and

- $\quad$ changes in types of users.

Subsequently Swanson (1994) described IS process innovations in his so-called "tri-core" model as covering three aspects of the business - type I innovations confined to the IS task, type II innovations that support the administration of the business, and type III innovations embedded in the core technology of the business.

Mustonen-Ollila and Lyytinen (2003) identify four generations of IS process innovation. The first generation (from the late 1940s to the mid-1960s) was largely hampered by hardware costs and limitations in hardware capacity and reliability. The second generation (from the mid-1960s to the early 1980s) was characterized by poor productivity of systems developers and difficulties of delivering reliable systems on time and within budget. The third generation (from early 1980s to the beginning of 1990s) was driven by the challenge to overcome system quality problems arising from inadequate perception of user demand and resulting in inadequate service. Finally, the fourth generation (from the beginning of 1990s) was effected by complex interactions between computing systems and specific organizational agents including customers and clients, suppliers, competitors, co-operators, representatives and public bodies.

There have also been several IS Management frameworks developed to assist practitioners to manage the IS resource. Examples include the Capability Maturity Model (CMM), the International IT Library (ITIL), and the Control Objectives for Information and related Technology (COBIT), as well as the IT Capability Maturity Model (IT-CMF) (Curley, 2004, 2007).

From the practitioner community, thought leaders have emerged from product design and organizational design consulting firms. In 1991, Tom Kelly published The Art of Innovation: Lessons in Creativity from IDEO, America's Leading Design Firm IDEO, and articulated a 5-step methodology to guide teams through a process of innovation. The steps were:

1. Understand the market, the client, the technology and the perceived constraints on the problem

2. Observe real people in real-life situations to find out what makes them tick: what confuses them, what they like, what they hate, where they have latent needs no addressed by current products and services.

3. Visualize new-to-the-world concepts and customers who will use them

4. Evaluate and refine the prototypes in a series of quick iterations

5. Implement the new concept for commercialization

This approach has been adopted widely among the innovation practitioner community, including Chevron. The application of these innovation guidelines in Chevron was investigated as an example of 
how innovation processes are executed in practice and how they might relate to the guidelines of design science research.

\section{Case Study: The Application of an Innovation Process in Chevron}

The methodology described in Kelly (1991) has been refined over time and adapted by innovation practitioners to fit their particular organizational culture. Research conducted by Innovation Value Institute has identified many IT organizations -- including Intel, Northrop-Grumman, Merck, and Chevron -- that have tested this methodology and adapted it for use. In Chevron steps 3 and 4 of the IDEO methodology are changed to focus on Ideation (the creative process of generating, developing, and communicating new ideas and solutions), Refinement (iterating ideas until ready for demonstration), and Prototyping (the creation of early samples or models built to test a concept or process or to act as a thing to be replicated or learned from).

In 2008 Chevron IT, after testing and adpating the methodology to Chevron IT's culture and supporting practices, introduced its variation of the innovation methodology entitling it "The Innovation Cycle" and deploying it through a multi-day workshop entitled "Idea Storms". Chevron IT also applies components of the Innovation Cycle for specific business challenges in workshops entitled "Idea Jams". Over 150 Idea Storms and Idea Jams have been conducted.

This study explores Chevron IT's practical application of it's six-step Innovation Cycle:

1. Understand the market, the client, the technology and the perceived constraints on the problem

2. Observe real people in real-life situations to find out what makes them tick

3. Ideate by generating, developing, and communicating new ideas and solutions

4. Refine ideas into themes

5. Prototype early samples or models built to test a concept or process or to act as a thing to be replicated or learned from

6. Approve select prototyped ideas that will be implemented in production

The case study being analysed in this paper involves a Chevron "IT Idea Storm" innovation workshop conducted in May 2009 entitled "RAVE Application Extension" where RAVE refers to Chevron's Refinery Asset Virtual Environment. The workshop's goal was to identify innovative practical technical applications in Chevron for RAVE beyond the environment for which it was produced.

Participants from several functional technology oriented disciplines in Chevron were facilitaed through Chevron IT's Innovation Cycle beginning with "Understand" to insure clarity of the technology, it's current application and potential use beyond current use. Artefacts from this portion of the workshop include a document describing RAVE and its value (an excerpt follows). The critical aspects of the RAVE project were:

1. RAVE definition: RAVE - Refinery Asset Virtual Environment - was originally developed to simulate Chevron's Refinery environment. 3-D refinery asset models are incorporated with contextual data from multiple sources. A Web2.0 virtual room allows subject matter experts (SMEs), represented as avatars, to engage in remote collaboration, decision making, and work process scenarios.

2. RAVE business drivers: Directly increase Safety, Reliability, and Operational Performance, providing decision makers with the information they need, associated with a manufacturing asset, in a virtual collaborative space: collaboration with Chevron HAZOPs (Hazard and Operability) response team processes; Operator training; New plant model reviews; Knowledge capture; Immersive operations intelligence. 
3. RAVE value: Work processes executed repetitively in a RAVE environment: Improve organizational capability; Reduce costs for remote participation in decision making; Increase SME (Subject Matter Expert) participation with in-room ad-hoc context information; Improve work processe execution, reducing the risk of incidents and injuries; Lead to fewer and shorter unscheduled shutdowns.

Table 1 lists the DSR guidelines as articulated by Hevner et al (2004) and the corresponding activities in the Chevron Innovation Process in the context of the RAVE case study. Summary statements of DSR guidelines are described in the left column and corresponding Innovation Process activities and artefacts, as found in Chevron's RAVE case study, are listed in the column on the right. The case study indicates that innovative artefacts can take on many forms from documented research and concepts to articulation of decisions made during evaluation activities.

The ability to describe the output of each step in the innovation cycle as artefacts is an important breakthrough. It allows the innovation practitioner to understand and calculate the value of output from each step in the cycle. Understanding the business value of the innovation process is one of the major problems facing organizations today. Table 2 lists the artefacts generated at each stage of the Chevron Innovation Process. The volume of artefacts and representative examples from each step in the innovation cycle employed in the RAVE case study are shown.

\section{How Design Science Research Informs Innovation Processes}

Our thorough understanding and analysis of the Chevron case study has led to a number of key insights helping us identify how design science research might inform the innovation process. Based on our initial analysis, we find five areas of potential DSR contribution.

\subsection{Artefacts}

The Innovation literature focuses on the contribution of the artefact to the application environment and the 'adopting unit.' On the other hand, DSR requires a contribution to both the application environment and to the field's knowledge base.

The case study indicates that innovative artefacts can take on many forms of abstract knowledge (e.g. models, architectures, methods), as well as, physical or systems-based instantiations. Current innovation processes, as exemplified by the application of the IDEO innovation approach in Chevron, focus on the outcome of the overall process rather than the artefacts that are created at each stage of the process.

The identification and analysis of artefacts created throughout the entire innovation process may well be a core differentiator between DSR and Innovation and is worth exploring in future research.

\subsection{The Central Role of Evaluation}

DSR guidelines stress the importance of evaluation of utility, quality, and efficacy. Apart from an effort by Venkatesh and Davis (2000) to establish evaluation criteria for disruptive innovations, there is little evidence of extensive use of evaluation methods in the innovation process, although there is a very extensive literature on technology acceptance models (Davis 1989). It is not clear how innovators appropriately select evaluation methods to provide convincing evidence of their artefact's utility and qualities? We posit that the emphasis on evaluation in DSR could have great potential to inform innovation processes.

In the case study, evaluation of the quality of resulting innovation steps is based on the Innovation Challenge artefact with the exception of the initial stages of step 3 (Ideation), and step 5 (Prototyping) when open ideas and concepts are accepted without judgment. Evaluation in each step in the RAVE workshop used the RAVE value descriptors as documented in the Table 1 description of RAVE. 


\section{Table 1 Design Science Guidelines vs. Chevron's Innovation Process}

\begin{tabular}{|c|c|c|}
\hline Design Science Process Guidelines (Hevner et al. 2004) & & Innovation Process Artefacts [based on (Kelly 1991)] \\
\hline Design-science research must produce a viable artifact in & Innovation Ste & Artefact \\
\hline instantiation. & 1. Understand & Documented research \\
\hline & 2. Observe & Documented a) experiential research; b) documented reference points \\
\hline & 3. Ideate & Documented : Idea fragments; Themed ideas; Validated ideas; Archived ideas \\
\hline & 4. Refine & Documented concepts \\
\hline & 5. Prototype & Working models; Attribute documentation \\
\hline & 6. Approve & Management summary material; decision documentation \\
\hline $\begin{array}{l}\text { The objective of design-science research is to develop } \\
\text { technology-based solutions to important and relevant } \\
\text { business problems. }\end{array}$ & $\begin{array}{l}\text { Before the inno } \\
\text { "Innovation } \mathrm{Ch} \\
\text { Support; c) bus }\end{array}$ & $\begin{array}{l}\text { on cycle is applied a consultation step produces an artefact (Documented } \\
\text { ge") is produced to detail the business challenge's a) strategic fit, b) Organization } \\
\text { s application; d) timing requirements }\end{array}$ \\
\hline $\begin{array}{l}\text { The utility, quality, and efficacy of a design artifact must be } \\
\text { rigorously demonstrated via evaluation methods. }\end{array}$ & $\begin{array}{l}\text { Evaluation of } t \\
\text { with the except }\end{array}$ & $\begin{array}{l}\text { ality of resulting innovation steps is based on the Innovation Challenge artefact } \\
\text { f the initial stages of step } 3 \text { (Ideation), and step } 5 \text { (Prototyping). }\end{array}$ \\
\hline $\begin{array}{l}\text { Effective design-science research must provide clear and } \\
\text { verifiable contributions in the areas of the design artifact, } \\
\text { design foundations, and/or design methodologies. }\end{array}$ & $\begin{array}{l}\text { Only contributi } \\
\text { are in focus wit } \\
\text { a) Radic } \\
\text { b) Reapr } \\
\text { c) Incre }\end{array}$ & $\begin{array}{l}\text { hat are new and unique to the business group executing the Innovation Challenge } \\
\text { innovation process. We define new contribution as follows: } \\
\text { ntroduction of a new solution that changes the way we do buisness } \\
\text { : Adaption of a solution developed for another problem } \\
\text { al: Augmenting a previous solution with new elements }\end{array}$ \\
\hline $\begin{array}{l}\text { Design-science research relies upon the application of } \\
\text { rigorous methods in both the construction and evaluation } \\
\text { of the design artifact. }\end{array}$ & $\begin{array}{l}\text { Rigor is applie } \\
\text { Challenge is de } \\
\text { is provided wit } \\
\text { limit generativ } \\
\text { generate new i } \\
\text { initial steps of } t\end{array}$ & $\begin{array}{l}\text { fore and after application of the Innovation Cycle - (before) as the Innovation } \\
\text { and (after) as approved prototypes are implemented into production. Guidance } \\
\text { the innovation cycle to allow creative thinking and to avoid behavior that would } \\
\text { tput -- but in general the innovation cycle is used for fast, creative thinking to } \\
\text { With this rigor, structure, definition, and judgment are purposefully avoided in } \\
\text { leation and Prototyping steps. }\end{array}$ \\
\hline $\begin{array}{l}\text { The search for an effective artifact requires utilizing } \\
\text { available means to reach desired ends while satisfying laws } \\
\text { in the problem environment. }\end{array}$ & $\begin{array}{l}\text { With innovatio } \\
\text { new and unique }\end{array}$ & $\begin{array}{l}\text { rch thinking is tied to thinking about contribution as only contributions that are } \\
\text { e group executing the Innovation Challenge are in focus. }\end{array}$ \\
\hline $\begin{array}{l}\text { DSR must be communicated both to technology-oriented } \\
\text { as well as management-oriented audiences. }\end{array}$ & $\begin{array}{l}\text { Communicatic } \\
\text { collected in th }\end{array}$ & $\begin{array}{l}\text { ntained within workshop groups until ideas are elevated to prototypes. Ideas } \\
\text { on step are saved for future business challenges. }\end{array}$ \\
\hline
\end{tabular}




\section{Table 2 Artefacts Generated in The Chevron Innovation Process}

\begin{tabular}{|c|c|}
\hline $\begin{array}{l}\text { Innovation } \\
\text { Process Steps }\end{array}$ & Artefacts generated by Chevron "RAVE" Case Study \\
\hline 1. Understand & ee detail documented in introduction of RAVE above. \\
\hline 2. Observe & $\begin{array}{l}\text { Participants documented over } 30 \text { observations of RAVE and its potential application to Chevron, including this example: } \\
\text { "When I see the actual flow rate of a pipe via a meter and see how I could virtually view the pipe and the flow direction - it expands my } \\
\text { understanding of the environment exponentially - and triggers many ideas for monitoring and controls" }\end{array}$ \\
\hline 3. Ideate & $\begin{array}{l}\text { Idea Fragments } \\
69 \text { initial ideas (in the process we call these "idea fragments") were submitted including this incremental innovation example: } \\
\text { "Ability to walk through a virtual environment and "tag" an idea / question in the context" } \\
\text { And this reapplied innovation example: } \\
\text { "Apply RAVE Chevron Decision Support Centers -- remote decision support centers are nearer to reality than remote control rooms" } \\
\text { Idea Thems/Groups: } \\
\text { Workshop participants grouped idea fragments into } 6 \text { categories: } 1 \text { ) Patent worthy; 2) Research required; 3) Explore and Test; 4) Radical; 5) } \\
\text { Existing; 6) Discard } \\
\text { Validated ideas: } \\
\text { Workshop participants agreed to concentrate on } 6 \text { ideas (from the patent-worthy group) for detailed focus, including: } \\
\text { Actionable ideas: } \\
\text { Workshop participants agreed } 12 \text { ideas were relatively simple to implement and immediately actionable - and a workshop participant agreed } \\
\text { to take the ideas to production after workshop completion. An example: } \\
\quad \text { Areneral facility introduction / training overview for visitors and community leaders to be added" } \\
\text { The remaining } 5 \text { idea groups -- } 63 \text { idea fragments) were archived in our idea management tool for future reference. }\end{array}$ \\
\hline 4. Refine & articipants took the 6 patent-worthy ideas and produced descriptions of concepts using Chevron's IP process and forms \\
\hline 5. Prototype & $\begin{array}{l}\text { Through modelling exercises workshop participants produced descriptions of each patent-worthy concept, including conceptual, functional } \\
\text { and practical attribute description. }\end{array}$ \\
\hline 6. Approve & $\begin{array}{l}\text { Participants presented conceptual prototypes to Chevron's Patent Attorney assigned to the workshop. Through an iterative process } \\
\text { documented prototypes were refined to the point where Patent Attorneys could take documentation through the formal IP and then Patent } \\
\text { "production" process. }\end{array}$ \\
\hline
\end{tabular}




\subsection{Rigor}

DSR guidelines stress the application of rigor in the development process - as a means of enhancing the quality of the artefact that emerges from the process. A corresponding emphasis on rigor in construction and evaluation is not to be found in the Innovation literature although Cooper's (1994) Stage Gate Model does offer a systematic approach containing reviews of decisions at critical phases of the development process. We would argue that rigor in innovation processes is just as essential as in DSR. Attention to the most appropriate and effective techniques for building and evaluating the innovation is critical to an innovation's acceptance and success in the market place.

The Chevron Innovation Manager noted that 'in companies that don't have a rigorous innovation practice, people with new ideas don't know what to do with them and don't know whether their ideas are harvested or not. In the absence of evaluation criteria, or where the criteria is poorly defined and ad hoc, idea selection can appear to be arbitrary or as a result of bias. Innovation processes that are not executed well can result in demotivating employees and killing their creative contributions. Evaluation is probably the heart of an effective innovation practice because it articulates the criteria by which ideas are selected... and promotes the innovative behaviour that enables contributors to be recognized and rewarded".

In the Innovation Process implemented in Chevron, rigor is applied before and after application of the Innovation Cycle - (before) as the Innovation Challenge is defined and (after) as approved prototypes are implemented into production.

Guidance is provided within the innovation cycle to facilitate creative thinking and to avoid behavior that would limit generative output -- but in general the innovation cycle is used for fast, creative thinking to generate new ideas. With this rigor, structure, definition, and judgment are purposefully avoided in initial steps of the Ideation and Prototyping steps. Evaluation in each step in the RAVE workshop used the RAVE value descriptors documented in the introduction of RAVE above.

\subsection{Search}

In the case study, only contributions that are new and unique to the group executing the Innovation Challenge are in focus, so there is an onus on members of the innovation community to perform relevant searches. The RAVE workshop leveraged the business knowledge of participants to identify ideas as unique or redundant.

The focus for communication is within workshop groups until ideas are elevated to prototypes. Ideas collected in the Ideation step are saved for future reference, to add to the body of organization knowledge with the hope of application to future business challenges. Concepts presented to the Patent Attorneys were held privately during the IP and Patent Search formal processes. All other ideas and concepts were stored in Chevron's IT Management tool and made available for future use.

While we found a number of similarities between the search processes for design artefacts in DSR and the Chevron innovation process, we believe that further study is needed to understanding the relationships between the methods for searching complex solution spaces for innovations and design solutions.

\subsection{Contributions and Value}

DSR guidelines stress that clear and verifiable contributions in the areas of the design artifact, design foundations, and/or design methodologies are required. In parallel the innovation cycle stresses the drive for solutions that are new, value-added contributions to the organization applying them.

The study looked at the value of artifacts throughout the innovation cycle which lead to important findings that are useful to business, as understanding the business value of the innovation process is one of the major problems facing organizations today. Only contributions that are new and unique to the 
business group executing the Innovation Challenge are in focus with the innovation process. Chevron defines new contribution in three categories:

1. Radical: Introduction of a new solution that changes the way we do business

2. Reapplied: Adaption of a solution developed for another problem

3. Incremental: Augmenting a previous solution with new elements. The RAVE workshop leveraged the business knowledge of participants to identify ideas as unique or redundant.

We note the similarity of these three categories with the Knowledge Contribution Framework proposed by Gregor and Hevner (2011) as shown in Figure 1. The radical contribution aligns with invention. The reapplied contribution aligns with exaptation. The incremental contribution aligns with improvement. Thus, we claim that the production of value in the IDEO process can be expanded to include the DSR guidelines of contributions to both the research knowledgebase and the practical application environment. Future research will explore this claim.

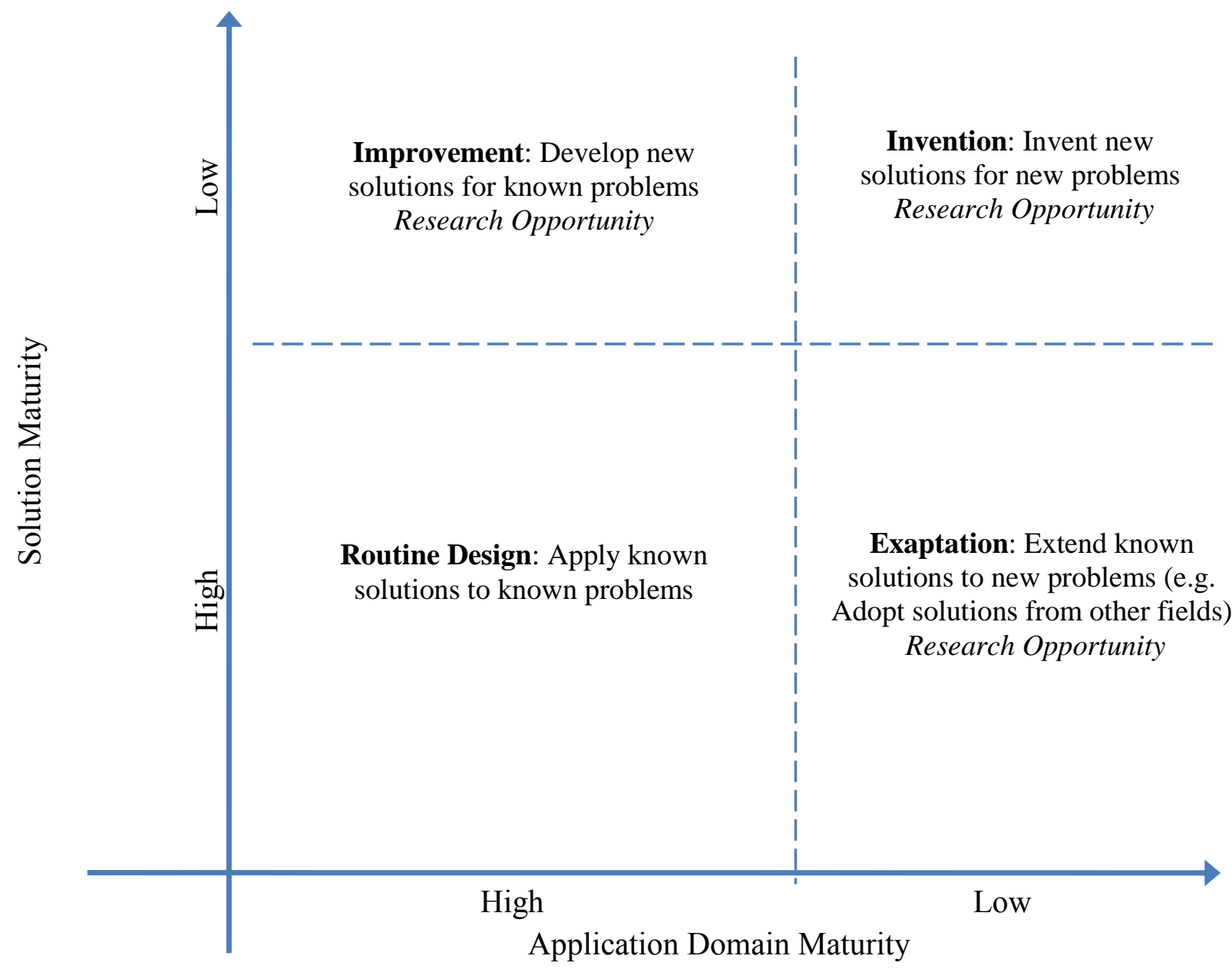

Figure 1: The Knowledge Contribution Framework (from Gregor and Hevner 2011)

\section{Research Approach}

This research is being undertaken in conjunction with the Innovation Value Institute (www.ivi.ie). Applying the principles of engaged scholarship (Van de Ven 2007, Mathiassen and Nielsen 2008), ICTS Innovation is being investigated using a design process with defined review stages and development activities based on the DSR guidelines advocated by Hevner et al. (2004). During the design process, 
researchers participate together with practitioners within research teams to capture the views of key domain experts. Using a case study approach supported by semi-structured interviews, researchers investigate the practice of innovation in some of its consortium members. A focus of the research is the design decisions and rationale underpinning innovation processes so that the relationship between DSR and Innovation might be better understood.

Among its 60+ members the IVI has many leading exemplars of IT Innovation practice including Intel, Chevron, Microsoft, SAP, etc. This collaborative community of like-minded peers are committed to investigating and advancing tools and best practices associated with IT-enabled Innovation. The consortium provides an ideal opportunity to conduct a series of in-depth case studies, across a range of innovative organizations, leading to insights into the relationship between DSR and Innovarion. Our next step in our research approach will be to formulate a set of research questions based on the results of the Chevron case study analysis discussed above. We will then refine these questions with the help of industry advisors to determine areas of greatest impact to advance innovation in our targeted case study companies.

\section{Summary and Conclusions}

The research fields of DSR and Innovation are firmly established as important aspects of IS research. They continue to evolve rapidly, with research agendas driven by researchers with deep expertise in either of the two fields. However, little attention has been given to identifying how the concepts of DSR and Innovation impinge on each other. An investigation based on a case study of the innovation process implemented in Chevron suggests that there are key insights that can be drawn from the DSR guidelines that can potentially impact and improve organizational innovation processes. Our research addresses the opportunity to explore how the concepts in DSR might inform Innovation. A future objective is to also explore the impacts going the other direction - How can successful innovation processes inform and improve our DSR activities. Further future research will be conducted under the aegis of the Innovation Value Institute - a consortium of leading companies engaged in various forms of ICTS innovation.

\section{References}

Adams, R., Bessant, J. and Phelps, R. (2006) Innovation Management Measurement: A Review. International Journal of Management Reviews 8 (1), 21-47.

Avgerou, C. (2002) New Socio-Technical Perspectives of IS Innovation in Organizations. In ICT Innovation: Economic and Organizational Perspectives (Avgerou, C. and Larovere, R. L., Eds), pp 141-161, Edward Elgar, Cheltenham.

Benbasat, I. and Zmud, R. (1999) Empirical Research in Information Systems: The Question of Relevance, MIS Quarterly 23(1), 3-16.

Benbasat, I. and Zmud, R. (2003) The Identity Crisis within the IS Discipline: Defining and Communicating the Discipline's Core Properties, MIS Quarterly 27(2), 183-194.

Cooper, R. (1994) Developing New Products On Time, In Time, Product Innovation Management 11(5).

Costello, G. and Donnellan, B. (2008) Seeking The Face Of Innovation With The Ethical Compass Of Emmanuel Levinas, Open IT-based Innovation, International Federation for Information Processing IFIP WG8.6, Universidad Politécnica de Madrid, October 2008. Boston: Kluwer Academic Publishers.

Cross, N. (2001) Designerly Ways of Knowing: Design Discipline vs. Design Science, Design Issues 17(3), 49-55.

Curley M., Managing Information Technology for Business Value, Intel Press, 2004.

Curley M, Introducing an IT Capability Maturity Framework,. Proc. 9th International Conference in Enterprise Information Systems, Springer, 2007, pp. 21.26.

Damanpour F. 1991. Organizational innovation: a meta-analysis of effects of determinants and moderators. Acad. Mgmt. J. 34: 555.90

Downs Jr., G. W. and Mohr, L. B. (1976) Conceptual Issues in the Study of Innovation Administrative Science Quarterly 21 (4), 700-714.

Davis, C. (1996) Levinas : an introduction. Polity Press, Cambridge, UK. 
Fagerberg, J., Mowery, D. and Nelson, R. (Eds.) (2005) The Oxford Handbook of Innovation, edited by Oxford University Press, Oxford.

Feeney, D. and Wilcocks, L. (1998) Core IS Capabilities for Exploiting Information Technology, Sloan Management Review, Spring, 9-21.

Garcia, R. and Calantone, R. (2002) A Critical Look at Technological Innovation Typology and Innovativeness Terminology: A Literature Review, Journal of Product Innovation Management 19 (2), 110-132.

Gregor, S. and Hevner, A. (2011) Positioning and Presenting Design Science Research for Maximum Impact, White Paper submitted for publication.

Hevner, A., March, S., Park, J., and Ram, S. (2004) Design Science in Information Systems Research, MIS Quarterly, 28(1), 75-105.

Hevner, A. (2007) A Three-Cycle View of Design Science Research, Scandinavian Journal of Information Systems, 19( 2) 87-92.

Kautz, K. and Nielsen, P. A. (2004) Understanding the Implementation of Software Process Improvement Innovations in Software Organisations. Information Systems Journal 14 (1), 3-22

Kelly, T. (2001) The Art of Innovation: Lessons in Creativity from IDEO, America's Leading Design Firm, Doubleday, New York.

Knight, K. E. (1967) A Descriptive Model of the Intra-Firm Innovation Process. The Journal of Business 40 (4), 478-496.

Mathiassen, L. and Nielsen, P. (2008) Engaged Scholarship in IS Research, Scandinavian Journal of Information Systems 20(2).

McNerney, J. (2001) Footbridge towards the Other: A Philosophical Investigation into the Notion of the Human Person in the Writings of Karol Wojtyla : With Special Reference to the Paradigm of the Neighbour M.Litt Thesis ,Department of Philosophy, University College Dublin, Ireland.

Nightingale, P. (1998) A Cognitive Model of Innovation. Research Policy 27(7) 687-709.

Orlikowski, W. and Iacono, S. (2001) Research Commentary: Desperately Seeking the 'IT' in IT Research: A Call for Theorizing the IT Artifact, Information Systems Research 12, 121-134.

Peppard, J., Lambert R. and C. Edwards, (2000) Whose Job is it Anyway?: Organizational Information Competencies for Value Creation, Information Systems Journal 10, 291-322.

Peppard J. and Ward J. (2004) Beyond Strategic Information Systems: Towards an IS Capability, Journal of Strategic Information Systems 13, 167-190.

Porter, M., (1998) Clusters and the new economics of competition, Harvard Business Review, Nov/Dec98, Vol. 76 Issue 6, p77.

Rahmanseresht, H. (1988) Towards a Revised Model of Innovation in Organisations, Ph.D.. Thesis, University of Hull.

Schumpeter, J. A. (1943) Capitalism, Socialism, and Democracy. Routledge, 6th ed. Pp. 81-84

Shavinina, L. (Ed.) (2003) The International Handbook on Innovation. Elsevier, Oxford.

Slappendel, C. (1996) Perspectives on Innovation in Organizations, Organization Studies 17(1), 107-129.

Simon, H. (1996) The Sciences of the Artificial, $3^{\text {rd }}$ Edition, Cambridge, Massachusetts, MIT Press.

Swanson, E. (1994) Information Systems Innovation among Organizations, Management Science 40(9), $1069-1088$.

Venkatesh V. and Davis F. (2000) A Theoretical Extension of the Technology Acceptance Model: Four Longitudinal Field Studies, Management Science 46, 186-204.

Van de Ven A. (2007) Engaged Scholarship: A Guide for Organizational and Social Research, Oxford Univ. Press.

Weber, R. (1987) Towards a Theory of Artifacts: A Paradigmatic Base for Information Systems Research, Journal of Information Systems 1(1) 3-20.

Webster, J. and Watson, R. (2002) Analyzing the Past to Prepare for the Future: Writing a Literature Review, MIS Quarterly 26(2), xiii-xxiii.

Wolfe, R (1994) Organizational Innovation: Review, Critique and Suggested Research Directions, Journal of Management Studies 31(3) 405-431.

Zain, M. (1993) A Field Study of Adoption and Implementations of Innovations by Manufacturing Firms in Malaysia, Ph.D. Thesis, Manchester Business School.

Zaltman, G., Duncan, R. and Holbek, J. (1973) Innovations and Organizations. Wiley, New York. 